\title{
Correction to: Working conditions and occupational stress among nurses in Bangladesh: a cross-sectional pilot study
}

\author{
Md Irteja Islam 1,2,3 $\cdot$ Kh Md Watin Alam ${ }^{4,5}$ - Syed Afroz Keramat ${ }^{3} \cdot$ Munzur E. Murshid $^{6} \cdot$ Rezwanul Haque $^{7}$. \\ Enamul Kabir ${ }^{2,8} \cdot$ Rasheda Khanam ${ }^{2,3}$ - Manjurul Haque Khan ${ }^{4}$
}

Published online: 4 March 2021

(C) Springer-Verlag GmbH Germany, part of Springer Nature 2021

\section{Correction to: J Public Health (Berl.): From Theory to Practice https://doi.org/10.1007/s10389-020-01415-8}

The affiliation has a little modification for author Rezwanul Haque.

Affiliation given: American International University of Bangladesh

Correct affiliation: American International UniversityBangladesh (AIUB)

The original article has been corrected.

Publisher's note Springer Nature remains neutral with regard to jurisdictional claims in published maps and institutional affiliations.

The online version of the original article can be found at https://oi.org/ 10.1007/s10389-020-01415-8

Md Irteja Islam

irteja.islam@icddrb.org; mdirteja.islam@usq.edu.au

1 Maternal and Child Health Division, International Centre for Diarrhoeal Disease Research, Bangladesh, Dhaka, Bangladesh

2 Centre for Health Research, University of Southern Queensland, Toowoomba, Australia

3 School of Commerce, University of Southern Queensland, Toowoomba, Australia

4 Department of Occupation and Environmenal Health, Naitonal Institute of Preventive and Social Medicine, Dhaka, Bangladesh

5 Child Health Research Foundation, Dhaka, Bangladesh

6 Handicap International - Bangladesh, Dhaka, Bangladesh

7 American International University-Bangladesh (AIUB), Dhaka, Bangladesh

8 School of Sciences, University of Southern Queensland, Toowoomba, Australia 